\title{
Outcomes of Severely Malnourished Children Aged 6 - 59 Months on Outpatient Management Program in Kitui County Hospital, Kenya
}

\author{
Dorothy Mbaya ${ }^{1,2 *}$, Lucy Kivuti Bitok ${ }^{2}$, Anna K. Karani², Boniface Osano3 ${ }^{3}$ Michael Habtu ${ }^{4}$ \\ ${ }^{1}$ Chuka District Hospital, Chuka, Kenya \\ ${ }^{2}$ School of Nursing Sciences, College of Health Sciences, University of Nairobi, Nairobi, Kenya \\ ${ }^{3}$ Department of Pediatrics and Child Health, School of Medicine, College of Health Sciences, University of \\ Nairobi, Nairobi, Kenya \\ ${ }^{4}$ Institute of Tropical Medicine and Infectious Diseases, Jomo Kenyatta University of Agriculture and \\ Technology, Nairobi, Kenya \\ Email: "dmicheni10@gmail.com
}

Received 16 November 2015; accepted 21 December 2015; published 25 December 2015

Copyright (C) 2015 by authors and Scientific Research Publishing Inc.

This work is licensed under the Creative Commons Attribution International License (CC BY).

http://creativecommons.org/licenses/by/4.0/

(c) (i) 0pen Access

\section{Abstract}

Background: Severe acute malnutrition is a widely prevalent problem in developing countries and a major cause of morbidity and mortality. Traditionally, children with severe acute malnutrition were rehabilitated within inpatient services. Advent of ready to use therapeutic food made it possible to treat majority of these children in their homes. However, there is limited data about the outcomes of the program. Objectives: To determine the outcomes (recovery, default, mean weight gain and non-response rates) of severely malnourished children aged 6 - 59 months enrolled in outpatient therapeutic program at Kitui County Hospital. Methodology: A prospective longitudinal study design was carried out for one month. Hundred and four (104) children with SAM were recruited in the study. Anthropometric measurements, physical examination and appetite test of the children were conducted on a weekly basis for 28 days. Descriptive analysis was conducted using means, frequency and proportions. Paired $t$ test was computed for mean weight gain and mid-upper arm circumference between admission and subsequent visits. Results: The findings of the study revealed that the recovery rate was $73.3 \%$, weight gain rate of $5.1 \mathrm{~g} / \mathrm{kg} / \mathrm{day}$, defaulter rate was $2.9 \%$ and non-response rate was $13.9 \%(\mathrm{WHZ}=-3 \mathrm{SD})$. Mean weight increased from $6.8 \mathrm{~kg}$ on the $1^{\text {st }}$ visit to $7.5 \mathrm{~kg}$ in the $4^{\text {th }}$ visit $(P=0.000)$ and the meanmid-upper arm circumferenceincreased from $11.1 \mathrm{~cm}$ at admission to $11.9 \mathrm{~cm}$ at $4^{\text {th }}$ visit $(P=0.000)$. Conclusion: The recovery and weight gain rates were below the global acceptable SPHERE of minimum standards *Corresponding author. 
(recovery rate $>75 \%$ and weight gain rate $>8 \mathrm{~g} / \mathrm{kg} /$ day). The defaulter rate was within the acceptable international standards $(<15 \%)$.

\title{
Keywords
}

\author{
Default, Outcomes, Recovery Rate, Severe Acute Malnutrition, Weight Gain
}

\section{Introduction}

Severe acute malnutrition (SAM) is defined by an extremely low weight for height, by visible severe wasting (marasmus), and/or by the presence of nutritional oedema (kwashiorkor). SAM or wasting is measured by one or more of the following criteria: Weight-for-height (WFH) $\leq-3$ Z-scores; Weight-for-height less than $70 \%$ of the median; Mid-upper arm circumference (MUAC) less than $115 \mathrm{~mm}$ and Presence of bilateral pitting oedema [1].

Worldwide nearly 24 million children (younger than 5 years) experience SAM and 19 million severely wasted children are living in developing countries. It is common in sub-Saharan Africa, with approximately 3\% of children less than five years affected at any one time. It is associated with several hundred thousand child deaths each year [2] [3]. An estimated 53\% of the preventable causes of death in children less than five years are attributed to malnutrition [4]. It also has negative implications for morbidity, long-term growth, cognitive and behavioural development, and work capacity among survivors [5].

The outpatient therapeutic program (OTP) offers services to severely malnourished children age 6 - 59 months. Until recently, the management of SAM has been limited to hospital cares with limited coverage [6]. OTP brings the service of management of SAM closer to the community by making services available at decentralized health facilities (primary health care units) in different resource limited countries [7]. It is operational at health centers and health posts and offers the lifesaving treatments with ready-to-use therapeutic foods (RUTF), usually Plumpy'Nut. In addition to Plumpy'Nut, severely malnourished children are provided with routine medications such as de-wormers, antibiotics, vitamin A, folic acid and measles vaccine. Only children who have appetite with Plumpy'Nut and those who don't have medical complications are eligible to the OTP [8].

Practitioners and World Health Organization (WHO) experts endorse community-based management for uncomplicated SAM while still advising that children who are severely malnourished and have medical complications, such as severe oedema, should be treated in an appropriate health facility [9]. However, two trial studies comparing children treated in outpatient care after one week of stabilization in inpatient setting against full inpatient care have shown outcome discrepancies. The first trial in Malawi reported better results in outpatients than in inpatients (recovery: $72 \%$ vs $49 \%$ ) probably related to more infections in inpatient care and mortality rate was $5.4 \%$ in inpatient and 3.0\% for home-based therapy [10]. The second trial in Bangladesh reported the reverse (recovery: $67 \%$ vs $86 \%$ ) but no food supplement was provided to outpatients and mortality rate was $3.5 \%$ in inpatient, $5 \%$ in day care and $3.5 \%$ at home (after one week of day care) [11].

Although the prevalence of malnutrition in Kenya especially Eastern province including Kitui County is still high, the outcome data on outpatient therapeutic program of severe acute malnourished children is still unclear. This study, therefore, sought to establish the outcomes of outpatient therapeutic program among children aged 6 - 59 months with SAM in Kitui County Hospital.

\section{Materials and Methods}

\subsection{Study Setting}

The study was carried out in Kitui County Hospital. It has a catchment population of 75,000 and serves as the main referral hospital in the Southern part of Kitui County. It has a bed capacity of 200 beds and 44 cots and an outpatient department with an OTP. Patients enrolled to OTP are detected from maternal and child health (MCH) clinics after routine screening, those referred from in-patient of the hospital or referred by community health workers (CHWs). 


\subsection{Study Design}

A short prospective longitudinal study was conducted among children aged 6 - 59 months with SAM enrolled under OTP. Each child was followed for 4 weeks on a weekly basis.

\subsection{Study Population and Sampling Technique}

Children aged 6 - 59 months enrolled in OTP were recruited into the study. Children with poor appetite, edema and medical complications were excluded. SAM was determined by WHO reference classification $\mathrm{W} / \mathrm{H}<-3$ Z-score, MUAC $<11.5 \mathrm{~cm}$, a good appetite, no medical complications and no severe edema (do not have moderate or severe edema).There were 104 children consecutively recruited to the study as they came to OTP. The sample size was calculated using Israel [12] formula $\left[n=N / 1+N(e)^{2}\right]$; where $n=$ the sample size, $N=$ the population, $e=$ margin of error (5\%).

\subsection{Data Collection Tools and Data Quality Control}

The anthropometric measurements (weight, height/Length and left mid upper arm circumference) were obtained using a follow up checklist in a private room within the OTP clinic. In addition, physical examination and appetite test were conducted. The anthropometric measurements were conducted at the onset then weekly for 4 weeks.

Research assistants were trained on data collection tools and procedures of the study before the actual study commenced. Quality assurance was maintained through monitoring of data collection activities on daily and weekly basis by the principal investigator. The weighing machines were calibrated for validity and standardization of reporting was ensured.

\subsection{Outcome Measures}

The main outcomes in the study were recovered (cured), defaulted, failure to respond and mean weight gain.

Recovered was defined when children attained target W/H -2 Z-score, MUAC $>11.5 \mathrm{~cm}$ and no edema for two consecutive visits and has attained discharge criteria.

Defaulter referred to a child that was absent for two consecutive weeks and confirmed that the patient is not dead by home visit.

Non-respondent is a patient that has not reached discharge criteria after staying under OTP intervention for 28 days.

Mean weight gain is the difference between two weights taken on admission and on $4^{\text {th }}$ visit divided by the number of intervening days; and then by the mid-point of the two weights. The units of mean weight gain were grams per kilogram per day.

\subsection{Data Management and Analysis}

After data collection, cleaning and validation was done and then entered into a Statistical Package format (using SPSS version 20.0) ready for analysis. Descriptive analysis using means, frequency and proportions was computed. Paired $t$ test $(\mathrm{P}<0.05)$ was computed for continuous variables (mean weight gain and MUAC) between admission and subsequent visits.

\subsection{Ethical Considerations}

Study approval was sought from the Ethics and Research Committees of the Kenyatta National Hospital/University of Nairobi (KNH/UON) and administrative permission from the Kitui County Hospital. Voluntary informedwritten consent was obtained from all mothers/guardians of the child. Confidentiality was maintained while handling participants' information.

\section{Results}

\subsection{Characteristics of the Children}

We recruited 104 children aged 6 - 56 months, 44 (42.3\%) were males and 60 (57.7\%) were female children. As 
shown in Table 1, the highest age group were those aged 6 - 12 months 36 (34.6\%) followed by 13 - 18 months 29 (27.9\%).The mean age of the children was18 months. About a quarter 28 (26.9\%) of the children were first born.

\subsection{Outcomes of the Outpatient Therapeutic Program}

Of the 104 children enrolled into the study 3 (2.9\%) defaulted. Children with WHZ -2SD and above were classified as recovered while below $-2 \mathrm{SD}$ of $\mathrm{WHZ}$ were considered as not recovered. Out of the 101 children who were followed for four visits 74 (73.3\%) recovered and 27 (26.7\%) didn't recover. Fourteen children (13.9\%) failed to respond $(\mathrm{WHZ}=-3 \mathrm{SD})$ and only $7(6.9 \%)$ had attained full nutritional recovery $(\mathrm{WHZ}=-1 \mathrm{SD})$. More than half 55 (54.5\%) of the children had WHZ of -2 SD by fourth visit. The overall mean weight gain was 5.12 grams. About half of the children 49 (48.5\%) and 47 (46.5\%) had gained mean weight of 5 to $10 \mathrm{~g} / \mathrm{kg} / \mathrm{day}$ and $<5$ $\mathrm{g} / \mathrm{kg} /$ day respectively. However, there were only 5 (5.0\%) who gained mean weight of $>10 \mathrm{~g} / \mathrm{kg} / \mathrm{day}$ (Table 2).

Table 1. Characteristics of the children.

\begin{tabular}{cccc}
\hline Variables & \multicolumn{2}{c}{$\mathbf{n}=\mathbf{1 0 4}$} & $\mathbf{\%}$ \\
\hline & Age in months & \\
\hline $6-12$ months & 36 & 34.6 \\
$13-18$ months & 29 & 27.9 \\
$19-24$ months & 23 & 22.1 \\
$25-56$ months & & 16 & 15.4 \\
\hline & Sex & & \\
\hline Male & & 44 & 42.3 \\
Female & & 60 & 57.7 \\
\hline & Birth order & & \\
\hline First & & 28 & 26.9 \\
Second & & 22 & 21.2 \\
Third & 21 & 20.2 \\
Fourth & 14 & 13.5 \\
Fifth and above & & 19 & 18.3 \\
\hline
\end{tabular}

Table 2. Outcomes of the outpatient therapeutic program.

\begin{tabular}{|c|c|c|}
\hline Variables & $n=104$ & $\%$ \\
\hline \multicolumn{3}{|c|}{ Default } \\
\hline Yes & 3 & 2.9 \\
\hline No & 101 & 97.1 \\
\hline \multicolumn{3}{|c|}{ Recovery } \\
\hline Yes & 74 & 73.3 \\
\hline No & 27 & 26.7 \\
\hline \multicolumn{3}{|c|}{ Overall mean weight gain in grams $(5.12 \pm 2.5)$} \\
\hline \multicolumn{3}{|c|}{ Mean weight gain } \\
\hline$>10$ g/kg/day & 5 & 5.0 \\
\hline 5 to $10 \mathrm{~g} / \mathrm{kg} / \mathrm{day}$ & 49 & 48.5 \\
\hline$<5$ g/kg/day & 47 & 46.5 \\
\hline \multicolumn{3}{|c|}{ WHZ on $4^{\text {th }}$ visit } \\
\hline$-1 \mathrm{SD}$ & 7 & 6.9 \\
\hline$<-1 \mathrm{SD}$ and $>-2 \mathrm{SD}$ & 11 & 10.8 \\
\hline$-2 S D$ & 56 & 55.4 \\
\hline$<-2 \mathrm{SD}$ and $>-3 \mathrm{SD}$ & 13 & 12.9 \\
\hline$-3 S D$ & 14 & 13.9 \\
\hline
\end{tabular}




\subsection{Trend and Comparison of Mean Weight and MUAC}

Figure 1 shows the mean trend of weight and MUAC among children enrolled in the outpatient management program for 4 weeks duration. The figure shows that the mean weight and MUAC increased over the four weeks of follow up till the $4^{\text {th }}$ visit.

Paired samples $t$ test was computed to determine the mean differences of weight and MUAC between the visits (Table 3). There was significant differences between the mean weights of $1^{\text {st }}$ visit and $2^{\text {nd }}$ visit $(P=0.000)$, $1^{\text {st }}$ visit and $3^{\text {rd }}$ visit $(P=0.000)$ as well as $1^{\text {st }}$ visit and $4^{\text {th }}$ visit $(P=0.000)$. Likewise, the mean MUAC was significantly higher between $1^{\text {st }}$ visit and $3^{\text {rd }}$ visit $(\mathrm{P}=0.000)$ as well as between $1^{\text {st }}$ visit and $4^{\text {th }}$ visit $(\mathrm{P}=0.000)$. However, the mean MUAC between $1^{\text {st }}$ visit and $2^{\text {nd }}$ visit was not significant $(\mathrm{P}=0.143)$.

\section{Discussion}

The recovery rate in this study (73.3\%) was lower than the international standards which set the lower threshold at $75 \%$. The rate is lower than findings from studies carried out in Southern Ethiopia which shows $87 \%$ [13] and in Southern Malawi where the recovery rate was 89\% [14]. However, it was higher than the study done in Nairobi which reported 58\% [15] and in Tigray Northern Ethiopia (61.78\%) [16]. These discrepancies could be as a result of differences in adherence to optimal management of children under OTP across regions, low frequency of feeding per day and sharing of the Plumpy'Nut with other members of the household which is a likely predictor of poor recovery of children treated at home. It was reported that sharing of RUTF with other family members, mostly children, was justified by social norms favoring sharing of food, a shortage of food in the household, the good taste of RUTF and its perceived good treatment properties [17].

In addition, genetic variations among SAM children may play a role in the recovery rate. Results from several ethnic groups (Bagandan, Peruvian, Chilean, South African Coloured) show that previously malnourished children do not attain, at least for several years, the weight, height, and bone age as children of the same ethnic background but of a higher social class [18] [19]. Considering that children from a higher social class may be nutritionally above average.

The overall defaulter rate $(2.9 \%)$ was well within the minimum international standard $(<15 \%)$. This figure is lower as compared to similar studies conducted on RUTF based therapeutic feeding programs in Maradi-Niger [20], Darfur-Sudan [21], Bedawacho-Ethiopia and Arbegoba-Ethiopia [22] [23]. This may signify that the

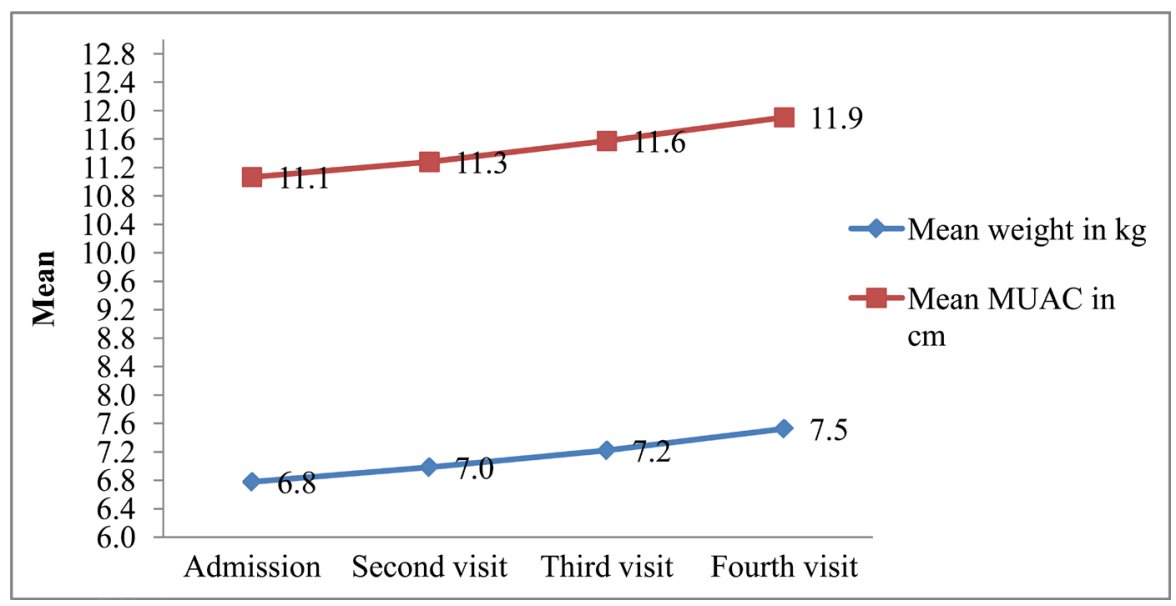

Figure 1. Trend of mean weight and MUAC between admission and consecutive visits.

Table 3. Comparison of mean weight and MUAC between first and consecutive visits.

\begin{tabular}{|c|c|c|c|c|c|c|}
\hline Variables & $\begin{array}{l}\text { Paired } t \text { test } \\
\text { between } 1^{\text {st }} \\
\text { and } 2^{\text {nd }} \text { visit }\end{array}$ & $\begin{array}{c}\text { Mean difference } \\
(95 \% \mathrm{CI})\end{array}$ & $\begin{array}{l}\text { Paired } t \text { test } \\
\text { between } 1^{\text {st }} \\
\text { and } 3^{\text {rd }} \text { visit }\end{array}$ & $\begin{array}{l}\text { Mean difference } \\
\text { (95\% CI) }\end{array}$ & $\begin{array}{l}\text { Paired } t \text { test } \\
\text { between } 1^{\text {st }} \\
\text { and } 4^{\text {th }} \text { visit }\end{array}$ & $\begin{array}{c}\text { Mean difference } \\
(95 \% \mathrm{CI})\end{array}$ \\
\hline Mean weight in kg & 0.000 & $0.20(0.16-0.25)$ & 0.000 & $0.43(0.38-0.40)$ & 0.000 & $0.70(0.65-0.80)$ \\
\hline Mean MUAC in cm & 0.143 & $0.21(-0.07-0.50)$ & 0.000 & $0.51(0.30-0.72)$ & 0.000 & $0.80(0.54-1.12)$ \\
\hline
\end{tabular}


mothers/guardians in the study area are aware about the consequences of defaulting from the program. It could also be attributed to shortage of food among the community/households which may compel them to attend the outpatient program for Plumpy'Nut/RUTF.

The mean weight gain of $5.12 \mathrm{~g} / \mathrm{kg} /$ day in this study was substantially less than the predicted rate based on the international standards which recommends weight gain of greater than or equal to $8 \mathrm{~g} / \mathrm{kg} / \mathrm{day}$. Yet it was higher compared to a similar study conducted in Nairobi which was 3.79/kg/day [15] and was comparable to a study conducted in Tigray Northern Ethiopia (5.24 g/kg/day) [16]. However, it was lower than in studies carried out by Chane et al. [24] (10.1 g/kg/day), by Hossain et al. [25] (10 g/kg/day) and by Gebremichael et al. [26] in Ayder referral in Ethiopia (10.7 g/kg/day). These discrepancies could have been due to differences in causes of malnutrition across various settings. In addition, the weights may not be taken on all visits and yet the RUTF should be given according to the body weight.

Even though the mean weight gain $(\mathrm{P}<0.000)$ and mean MUAC $(\mathrm{P}<0.000)$ were significantly different on admission and at $4^{\text {th }}$ visit, only (6.0\%) had attained nutritional recovery rate (defined as a WHZ equal to or greater than $-1 \mathrm{SD}$ ). About half (48.5\%) of the children had moderate to good mean weight gain (5 to 10 $\mathrm{g} / \mathrm{kg} /$ day), $46.5 \%$ had poor mean weight gain $(<5 \mathrm{~g} / \mathrm{kg} /$ day) and only $5.0 \%$ had good mean weight gain $(>10$ $\mathrm{g} / \mathrm{kg} /$ day). However, the findings are higher compared to study done in India by Patel et al. [27] during home based rehabilitation that reported only (11.5\%) children achieved weight gain of more than $5 \mathrm{gm} / \mathrm{kg} / \mathrm{day}$, while (89.5\%) children had weight gain of less than $5 \mathrm{gm} / \mathrm{kg} / \mathrm{day}$.

\section{Conclusion}

The recovery and weight gain rates in this study were below the acceptable standards of Global SPHERE. However, the defaulter rate was within the acceptable international standards.The findings highlight the need to enhance implementation of essential nutrition action approach during management of severe malnutrition in outpatient program.

\section{Acknowledgements}

The funding is from the Linked-Strengthening Maternal, Newborn and Child Health Research Training in Kenya. The grant is linked to Partnership for Innovative Medical Education in Kenya (PRIME-K). The project described was supported by Award Number 5R24TW008907 from the US National Institutes of Health. The content is solely the responsibility of the authors and does not necessarily represent the official views of the US National Institutes of Health. The authors would also like to sincerely appreciate all the study participants for their time and willingness to participate. The authors also give special thanks to the medical superintendent, data collectors and all staff members of Kitui County Hospital for their cooperation during the collection of data for this study and allowing us to conduct this research.

\section{Limitation}

During malnutrition low hemoglobin and serum albumin concentrations are common but due to financial constraints the study did not make provision for taking blood samples for biochemical information, therefore only anthropometric measurement were used.

\section{Competing Interests}

The authors declare that they have no competing interests.

\section{References}

[1] Isanaka, S., Villamor, E., Shepherd, S. and Grais, R.F. (2009) Assessing the Impact of the Introduction of the World Health Organization Growth Standards and Weight-for-Height Z-Score Criterion on the Response to Treatment of Severe Acute Malnutrition in Children: Secondary Data Analysis. Malnutrition in Children. Paediatrics, 123, e54-e59. http://dx.doi.org/10.1542/peds.2008-1375

[2] Collins, S., Sadler, K., Dent, N., Khara, T., Guerrero, S., Myatt, M., Saboya, M. and Walsh, A. (2006) Key Issues in the Success of Community-Based Management of Severe Malnutrition. Food and Nutrition Bulletin, 27, S49-S82. http://dx.doi.org/10.1177/15648265060273S304 
[3] Briend, A. and Collins, S. (2010) Therapeutic Nutrition for Children with Severe Acute Malnutrition Summary of African Experience. Indian Pediatrics, 47, 655-659. http://dx.doi.org/10.1007/s13312-010-0094-2

[4] Black, R.E., Morris, S.S. and Bryce, J. (2003) Where and Why 10 Million Children Are Dying Every Year? Lancet Child Survival Series 1, 361, 2226-2234.

[5] Alderman, H. (2006) Long Term Consequences of Early Childhood Malnutrition. Oxford Economic Papers, 58, 450474. http://dx.doi.org/10.1093/oep/gpl008

[6] Del, R. and Joy, M. (2008) Madagascar's Pilot Program for Community Management of Acute Malnutrition: Evaluation Highlights. Basic Support for Institutionalizing Child Survival (BASICS) for USAID 2008, Arlington.

[7] Lapidus, N., Luquero, F.J., Gaboulaud, V., Shepherd, S. and Grais, R.F. (2009) Prognostic Accuracy of WHO Growth Standards to Predict Mortality in a Large-Scale Nutritional Program in Niger. PLOS Medicine, 6, e1000039. http://dx.doi.org/10.1371/journal.pmed.1000039

[8] Econinck, H., Swindale, A., Grant, F. and Navarro-Colorado, C. (2008) Review of Community-Based Management of Acute Malnutrition (CMAM) in the Postemergency Context: Synthesis of Lessons on Integration of CMAM into National Health Systems. The Cases of Ethiopia, Malawi and Niger. FANTA Project, Academy for Educational Development, Washington DC.

[9] WHO (2013) Guideline Update: Technical Aspects of the Management of Severe Acute Malnutrition in Infants and Children. World Health Organization, Geneva.

[10] Ciliberto, M.A., Sandige, H., Ndekha, M.J., Ashorn, P., Briend, A., Ciliberto, H.M. and Manary, M.J. (2005) Comparison of Home-Based Therapy with Ready-to-Use Therapeutic Food with Standard Therapy in the Treatment of Malnourished Malawian Children: A Controlled, Clinical Effectiveness Trial. American Journal of Clinical Nutrition, 81, 864-870.

[11] Khanum, S., Ashworth, A. and Huttly, S.R. (1994) Controlled Trial of Three Approaches to the Treatment of Severe Malnutrition. The Lancet, 344, 1728-1732. http://dx.doi.org/10.1016/S0140-6736(94)92885-1

[12] Israel, G.D. (1992) Sampling: The Evidence of Extension Program Impact. Program Evaluation and Organizational Development, IFAS, University of Florida; PEOD-5. http://edis.ifas.ufl.edu/pdffiles/PD/PD00500.pdf3/6/2011

[13] Teferi, E., Lera, M., Sita, S., Bogale, Z., Datiko, D.G. and Yassin, M.A. (2010) Treatment Outcome of Children with Severe Acute Malnutrition Admitted to Therapeutic Feeding Centers in Southern Region of Ethiopia. Ethiopian Journal of Health Development, 24, 234-238.

[14] Dent, N. (2009) Outpatient Management of Acute Malnutrition in a Kenyan Urban Slum Context: Caseloads and Challenges. Malawi Medical Journal, 21, 123-159.

[15] Nalwa, G.M. (2012) Outcomes of Severely Malnourished Children Aged 6 to 60 Months on Outpatient Management in Nairobi.

[16] Yebyo, H.G., Kendall, C., Nigusse, D. and Lemma, W. (2013) Outpatient Therapeutic Feeding Program Outcomes and Determinants in Treatment of Severe Acute Malnutrition in Tigray, Northernethiopia: A Retrospective Cohort Study. PLOS ONE, 8, e65840.

[17] Tadesse, E., Berhane, Y., Hjern, A., Olsson, P. and Ekström, E. (2015) Perceptions of Usage and Unintended Consequences of Provision of Ready-to-Use Therapeutic Food for Management of Severe Acute Child Malnutrition. A Qualitative Study in Southern Ethiopia. Health Policy and Planning, 2015, 1-8.

[18] Messina, M.J. (1999) Legumes and Soybeans: Overview of Their Nutritional Profiles and Health Effects. American Journal of Clinical Nutrition, 70, 439S-450S.

[19] Perdigón, G., Nader de Macías, M.E., Álvarez, S., Oliver, G. and Pescede Ruiz Holgado, A. (1986) Effect of Perorally Administered Lactobacilli on Macrophage Activation in Mice. Infection and Immunity, 53, 104-410.

[20] Defourny, I., Drouhin, E., Terzian, M., Tatay, M., Sekkenes, J., et al. (2006) Scaling up the Treatment of Acute Childhood Malnutrition in Niger. Field Exchange, 28, 2-4.

[21] Taylor, A. (2002) Outpatient Therapeutic Programme (OTP): An Evaluation of a New SC UK Venture in North Darfur, Sudan. Taken from Field Exchange Issue 16, 2002.

[22] Chaiken, S., Deconinck, H. and Degefie, T. (2006) The Promise of a Community-Based Approach to Managing Severe Malnutrition: A Case Study from Ethiopia. Food and Nutrition Bulletin, 27, 95-104. http://dx.doi.org/10.1177/156482650602700201

[23] Collins, S. (2002) Outpatient Care for Severely Malnourished Children in Emergency Relief Programs: A Retrospective Cohort Study. The Lancet, 360, 1824-1830. http://dx.doi.org/10.1016/S0140-6736(02)11770-3

[24] Chane, T., Oljira, L., Atomesa, G.E. and Agedew, E. (2014) Treatment Outcome and Associated Factors among Under-Five Children with Severe Acute Malnutrition Admitted to Therapeutic Feeding Unit in Woldia Hospital, North Ethiopia. Journal of Nutrition \& Food Sciences, 4, 329. http://dx.doi.org/10.4172/2155-9600.1000329 
[25] Hossain, M.I., Dodd, N.S., Ahmed, T., et al. (2009) Experience in Managing Severe Malnutrition in a Government Tertiary Treatment Facility in Bangladesh. Journal of Health, Population and Nutrition, 27, 72-80. http://dx.doi.org/10.3329/jhpn.v27i1.3319

[26] Gebremichael, M., Bezabih, A.M. and Tsadik, M. (2014) Treatment Outcomes and Associated Risk Factors of Severely Malnourished under Five Children Admitted to Therapeutic Feeding Centers of Mekelle City, Northern Ethiopia. Open Access Library Journal, 1, e446. http://dx.doi.org/10.4236/oalib.1100446

[27] Patel, D., Gupta, P., Shah, D. and Sethi, K. (2010) Home-Based Rehabilitation of Severely Malnourished Children in Resource Poor Setting. Indian Paediatrics, 47, 694-710. http://dx.doi.org/10.1007/s13312-010-0102-6 